\section{$\underset{\substack{\text { hommes } \\ \text { \& migrations }}}{ }$}

\section{Hommes \& migrations}

Revue française de référence sur les dynamiques

migratoires

1286-1287 | 2010

Les migrations subsahariennes

\title{
Klaus Mann, Contre la barbarie 1925 - 1948
}

Paris, Phébus, 2009, 307 pages, 23 euros

\section{Mustapha Harzoune}

\section{(2) OpenEdition}

1 Journals

\section{Édition électronique}

URL : http://journals.openedition.org/hommesmigrations/1679

DOI : 10.4000/hommesmigrations. 1679

ISSN : 2262-3353

Éditeur

Musée national de l'histoire de l'immigration

Édition imprimée

Date de publication : 1 juillet 2010

Pagination : 308-309

ISSN : 1142-852X

\section{Référence électronique}

Mustapha Harzoune, « Klaus Mann, Contre la barbarie 1925 - 1948 », Hommes \& migrations [En ligne],

1286-1287 | 2010, mis en ligne le 19 juin 2013, consulté le 22 septembre 2020. URL : http://

journals.openedition.org/hommesmigrations/1679; DOI : https://doi.org/10.4000/

hommesmigrations. 1679

Ce document a été généré automatiquement le 22 septembre 2020.

Tous droits réservés 


\title{
Klaus Mann, Contre la barbarie 1925 - 1948
}

Paris, Phébus, 2009, 307 pages, 23 euros

\author{
Mustapha Harzoune
}

\section{RÉFÉRENCE}

Klaus Mann, Contre la barbarie 1925 - 1948, Préface de Michel Crépu, traduit de l'allemand par Dominique Laure Miermont et Corinna Gepner, Paris, Phébus, 2009, 307 pages, 23 euros

1 Contre la barbarie rassemble soixante-sept articles, textes de conférence et autres archives de l'écrivain allemand Klaus Mann écrits entre 1925 et 1948. La plupart de ces écrits signés par l'auteur de Méphisto et du Tournant sont inédits en France. C'est dire leur importance. Klaus Mann s'est exilé dès 1933, le 13 mars très exactement. Il fut déchu de sa nationalité par les nazis en 1934 et transforma son bannissement en une marque d'"honneur".

2 L'intérêt historique de ces textes ne doit pas masquer leur résonnance avec une actualité incertaine. D'ailleurs, Contre la barbarie est un titre sans doute volontairement imprécis : histoire de dire que l'attitude courageuse et la remarquable clairvoyance de Klaus Mann face au monstre nazi demeurent exemplaires à l'heure où peut-être de nouvelles barbaries se profilent... Ainsi, Klaus Mann montre qu'il y a des "confrontations " qui sont "indispensables" et qu'il faut se méfier "du désir de paix" des démocrates. Ce " désir" fut utilisé par Hitler "à des fins de chantage. On pouvait lui faire toutes les concessions qu'on voulait, il formulait de nouvelles exigences". "Avec des gens qui professent ce genre d'opinions, un homme civilisé n'a aucune chance de trouver un terrain d'entente, écrit-il en 1937. Il serait d'ailleurs vain de vouloir parler avec eux: leur 'idée fixe' ne permet pas de discussion raisonnable. Du reste, ils ne croient pas aux vérités, ils ne croient qu'en la force. On ne peut ni les apaiser, ni les convaincre; on ne réussit auprès d'eux qu'en ne montrant ni faiblesse, ni crainte, mais en étant déterminé, tout en restant civilisé." 
Dès 1931 Klaus Mann avertissait : "La psychologie permet de tout comprendre même les coups de matraque. Mais cette psychologie-là je ne veux pas la pratiquer. Je ne veux pas comprendre ces gens-là, je les rejette." Avec une langue implacable, une pensée claire, un style métallique et tranchant, le sens de la phrase et du rythme, Klaus Mann disait juste, voyait clair et loin, refusait tout compromis. Il ne se gêna pas pour dire leur fait aux dirigeants nazis. Il ne tergiversa pas non plus avec les intellectuels allemands, ces "gens méprisables" qui acceptèrent de fricoter avec le "régime de gangsters". Ils sont ici apostrophés publiquement, nommés, dénoncés, raillés et, in fine, au lendemain de la victoire, congédiés: "Une culture qui serait reconstruite par ceux-là ferait mieux de rester sous les décombres"... Pour Klaus Mann ces "célébrités" qui se sont prêtés à quelques accommodements et autres "lâchetés" sont davantage coupables que les nazis euxmêmes.

4 Il ne se priva pas aussi de pointer du doigt l'attitude du peuple allemand ou des démocraties européennes dans l'avènement et le succès du "baratineur à la petite moustache" (1934), "l'homme le plus criminel d'Europe", l'épouvantail assassin" (1935).

5 À plusieurs reprises, Klaus Mann cherche à attirer l'attention de ses lecteurs sur le sort des exilés. Il invite à écouter ces éclaireurs et à profiter de leur "experience" "c'est la seule chose que nous, les proscrits nous avons à vous offrir [...]". Sur cette question de l'immigration, il commence, toujours, sur la pointe des pieds, pour en arriver à suggérer, à dire, entre les lignes, les difficultés des exilés. Plutôt que de solliciter leur “ bienveillance capricieuse", il préfère inviter ses hôtes à un effort d'imagination en pensant "le mot 'émigration' dans toute l'étendue de sa fatalité et de sa gravité".

6 En ces temps où l'identité nationale titille quelques mauvais esprits, Klaus Mann est, une fois de plus, d'un grand secours. Il n'évoque pas, lui, l'identité allemande, mais il parle de "la nation à deux visages" ceux "de Goethe et de Göring, de Hitler et de Hölderlin". Ce "composé très curieux" est formé d'éléments dynamiques, mouvants, contradictoires, de sorte que "le caractère allemand s'est constitué à travers l'Histoire [et] non sous l'effet de données 'raciales' innées". Klaus Mann se bat pour "l'esprit", la "raison", la "civilisation" : “ La vie en société des êtres humains doit être réglée par la raison et non par un bazar irrationnel qui, au fond, cache des motivations très différentes et utilitaires". "Quand on ôte l'esprit, la vie devient impossible", prévient-il et l'esprit n'est pas seulement menacé par les militants toujours actifs des "bazars irrationnels", il peut aussi céder sous les coups de boutoir de ceux qui rabaissent la culture à un loisir, un passe-temps, un prêt-à-porter urbain, une marchandise...

7 "Il n'y a qu'un moyen d'empêcher que ne se reproduise une telle catastrophe: une solidarité parfaite, et l'organisation soigneusement planifiée de la paix à l'échelle du monde." Il est toujours possible de rêver de la paix à défaut d'en créer les conditions. Quant à la solidarité, il ne faudrait pas en sous-estimer l'importance. Comme prévient Klaus Mann, à propos des laissés-pour-compte - et par les temps qui courent, ils ne sont pas peu nombreux - "la mise à l'écart est certainement pire que la faim". Le risque serait alors que les "sirènes du nationalisme" - ou d'autres idéologies de fermeture - rendent inaudibles toute autre considération. 